\title{
Response of advanced cutaneous squamous cell carcinoma to immunotherapy: case report
}

\author{
Sara Ashraf, Mohamed Alsharedi \\ Joan C Edwards School of Medicine at Marshall University, Huntington, West Virginia, USA \\ Correspondence to: Sara Ashraf. Joan C Edwards School of Medicine at Marshall University, Huntington, West Virginia, USA. \\ Email: saraashraf87@yahoo.com.
}

\begin{abstract}
The most common cancer in the United States is non-melanoma skin cancer. Cutaneous squamous cell carcinoma (cSCC) is the second most common non-melanoma skin cancer after basal cell carcinoma. It develops in the middle and outer layers of the skin. Its precursor is actinic keratosis, which can progress to squamous cell carcinoma in situ, invasive cSCC, and finally metastatic cSCC. About 20\% of non-melanoma skin cancers are squamous cell and the remaining $80 \%$ are basal cell. Unlike basal cell, squamous cell carcinoma has the propensity to metastasize. This commonly occurs with squamous cell carcinoma (SCC) thicker than 2 millimeters. The risk of metastasis and local recurrence increases with $6 \mathrm{~mm}$ thickness and desmoplasia. The risk factors are excessive sun or ultraviolet light (tanning beds) exposure, immunosuppression (either having a weakened immune system or taking immunosuppressive therapy) and fair skin. Therefore, it most commonly affects skin in the head and neck area such as scalp, ears, lips, face, neck or the back of the hands. The treatment for local cutaneous squamous cell cancer is mainly surgery; excisional surgery, Moh's surgery, cryosurgery, curettage and electrodessication, laser surgery or radiation therapy, photodynamic therapy or topical agents such as fluorouracil or imiquimod. However, cSCC that is locally advanced, such as involvement of regional lymph nodes, or has metastasized to distant organs or tissue, is not amenable to surgery or radiation alone. Immunotherapy with cemiplimab, a programmed cell death 1 (PD-1) inhibitor, is a US Food and Drug Administration (FDA) approved therapeutic option for locally advanced and metastatic cSCC for patients who are not candidates for or whose disease is not susceptible to curative surgery or radiation therapy. Cemiplimab is a humanized recombinant immunoglobulin monoclonal antibody that binds to and blocks PD-1 receptor found on T cells inhibiting T-cell proliferation and cytokine production. We present a case of locally advanced cSCC with regional lymph nodes metastases, which achieved clinical remission, utilizing a unique approach of therapy combining a checkpoint inhibitor, Cemiplimab and radiotherapy.
\end{abstract}

Keywords: Cemiplimab; programmed cell death 1 (PD-1) inhibitor; advanced squamous cell carcinoma; radiotherapy; immunotherapy; case report

Received: 15 December 2020; Accepted: 15 June 2021; Published: 06 September 2021.

doi: $10.21037 /$ sci-2020-071

View this article at: https://dx.doi.org/10.21037/sci-2020-071

\section{Introduction}

Cutaneous squamous cell carcinoma (cSCC) is the second most common non-melanoma skin cancer after basal cell carcinoma (1).

cSCC of the head and neck is typically managed with Mohs Micrographic Surgery (MMS) with adjuvant radiation given to certain high-risk subsets (2).
Immunotherapy with cemiplimab, a programmed cell death 1 (PD-1) inhibitor, was approved for locally advanced and metastatic cSCC patients who are not amenable to curative surgery or radiation therapy (2). We sought to present this case with locally advanced and regional lymph nodes metastases, which achieved clinical remission, utilizing a unique approach of therapy combining a 


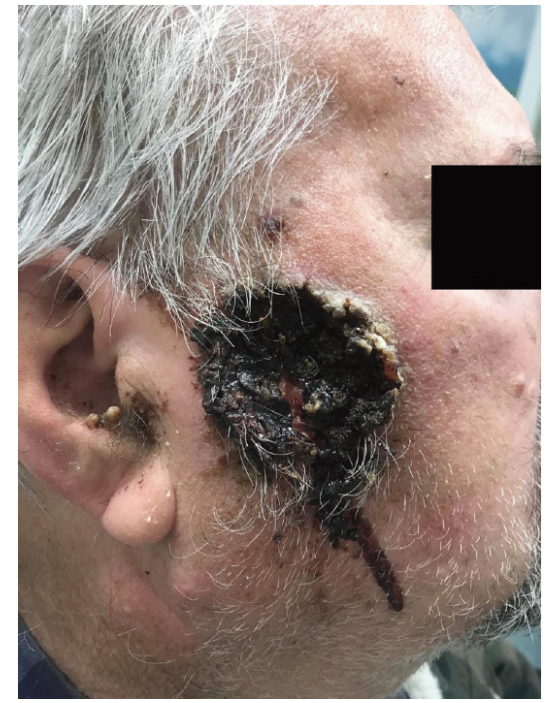

Figure 1 Friable, ulcerative mass prior to therapy.

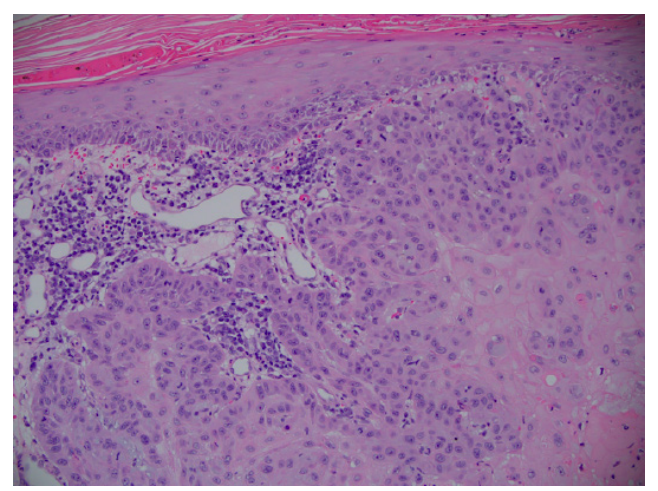

Figure 2 Lobules of keratinizing invasive squamous cell carcinoma invading the dermis (hematoxylin and eosin stain; 200x magnification).

checkpoint inhibitor and radiotherapy.

We present the following case in accordance with the CARE reporting checklist (available at https://dx.doi. org/10.21037/sci-2020-071).

\section{Case presentation}

A 73-year-old male with a past medical history of heavy cigarette smoking (2 packs per day for 40 years), coronary artery disease and previous stroke presented with a right sided facial lesion progressively enlarging and worsening over a period of 5 months. It was noted on physical examination to be a $5 \mathrm{~cm}$ right buccal skin necrotic ulcerative

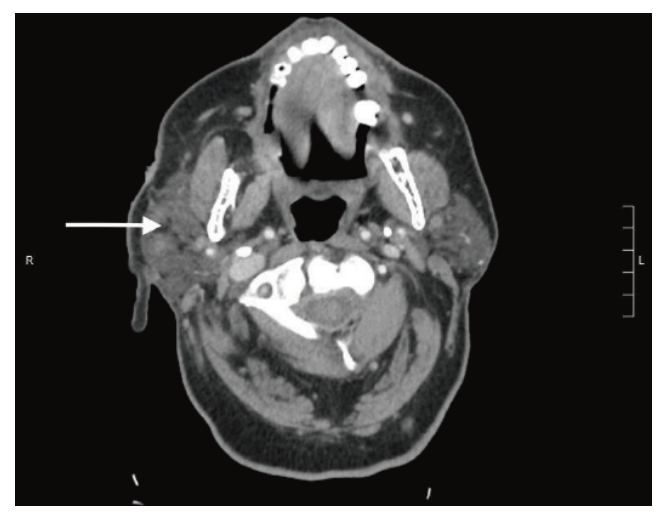

Figure 3 CT of the neck showing large soft tissue ulceration within the right temporal scalp and necrotic lymph nodes in the superior lateral, intraparotid and preauricular region.

lesion with raised borders and dried blood (Figure 1). There was a right conglomerate lymph node mass measuring $7 \mathrm{~cm}$ at the level of the mandible.

The patient underwent a shave biopsy with pathology consistent with a moderately differentiated invasive squamous cell carcinoma extending broadly to peripheral and deep biopsy edges (Figure 2).

He underwent computed tomography (CT) imaging with contrast of the head and neck which revealed the primary lesion having deep ulceration in the right temporal scalp at the level of the zygomatic arch. There was evidence of lymphatic metastases (Figure 3).

The patient was evaluated by plastic and reconstructive surgery and was deemed not to be a surgical candidate given the extent of the tumor. Given the patient had locally advanced, unresectable invasive cSCC, he was started on treatment with cemiplimab and radiation. After 4 cycles, the patient's tumor had a remarkable response (Figure 4). Patient tolerated it very well without any adverse effects and will continue on treatment at this time.

All procedures performed in studies involving human participants were in accordance with the ethical standards of the institutional and/or national research committee(s) and with the Helsinki Declaration (as revised in 2013). Informed consent was obtained from the patient for publication of this case report and any accompanying images.

\section{Discussion}

cSCC is a cancer of rapidly dividing epidermal keratinocytes (3). After melanoma, it is the most common cause of death from 


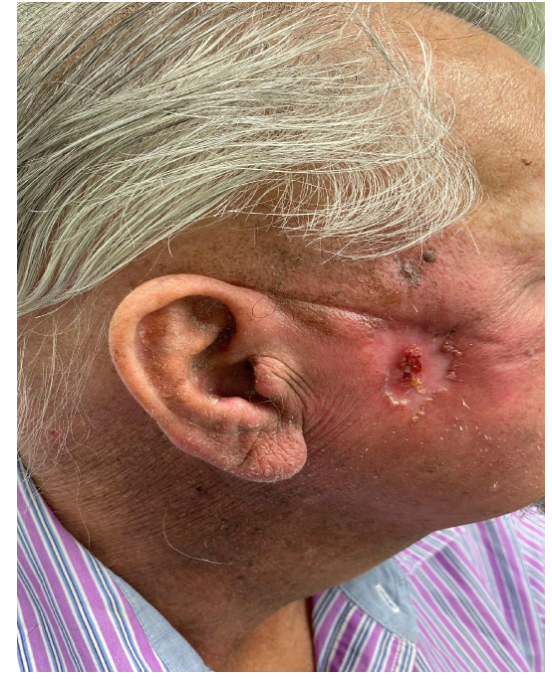

Figure 4 Response after 4 cycles of Cemiplimab with concurrent radiotherapy.

skin cancer (3). The incidence is felt to be underestimated, at 1 million cases each year in the US (3). Risk factors of cSCC include an immunosuppressed state, being elderly, male gender, fair skin, history of premalignant actinic keratosis and chronic sun exposure $(3,4)$.

The majority of cases are highly curable given localized disease, however when advanced or metastatic, it can cause significant morbidity and mortality (5). There are limited treatment options in this setting.

Cemiplimab is an antibody inhibiting PD-1 which gained approval by the US Food and Drug Administration (FDA) in September 2018. The drug showed strong efficacy in patients with locally advanced and metastatic disease. Objective response rates were seen in about $50 \%$ of patients (4). The recommended dose is $350 \mathrm{mg}$ given intravenously over 30 minutes every 3 weeks until disease progression or unacceptable toxicity. The tumor is thought to be highly sensitive to immunotherapy given high mutational load and increased risk of cSCC in immunosuppressed patients (4).

Immunotherapy has revolutionized the treatment paradigm for advanced cSCC giving patients like ours an easily tolerable treatment option with excellent response.

\section{Acknowledgments}

Funding: None.

\section{Footnote}

Reporting Checklist: The authors have completed the CARE reporting checklist. Available at https://dx.doi.org/10.21037/ sci-2020-071

Conflicts of Interest: Both authors have completed the ICMJE uniform disclosure form (available at https://dx.doi. org/10.21037/sci-2020-071). The authors have no conflicts of interest to declare.

Ethical Statement: The authors are accountable for all aspects of the work in ensuring that questions related to the accuracy or integrity of any part of the work are appropriately investigated and resolved. All procedures performed in studies involving human participants were in accordance with the ethical standards of the institutional and/or national research committee(s) and with the Helsinki Declaration (as revised in 2013). Informed consent was obtained from the patient for publication of this case report and any accompanying images.

Open Access Statement: This is an Open Access article distributed in accordance with the Creative Commons Attribution-NonCommercial-NoDerivs 4.0 International License (CC BY-NC-ND 4.0), which permits the noncommercial replication and distribution of the article with the strict proviso that no changes or edits are made and the original work is properly cited (including links to both the formal publication through the relevant DOI and the license). See: https://creativecommons.org/licenses/by-nc-nd/4.0/.

\section{References}

1. Que SKT, Zwald FO, Schmults CD. Cutaneous squamous cell carcinoma: incidence, risk factors, diagnosis, and staging. J Am Acad Dermatol 2018;78:237-47.

2. Varra V, Smile TD, Geiger JL, et al. Recent and Emerging Therapies for Cutaneous Squamous Cell Carcinomas of the Head and Neck. Curr Treat Options Oncol 2020;21:37.

3. Corchado-Cobos R, García-Sancha N, GonzálezSarmiento R, et al. Cutaneous Squamous Cell Carcinoma: From Biology to Therapy. Int J Mol Sci 2020;21:2956.

4. Migden MR, Rischin D, Schmults CD, et al. PD-1 blockade with cemiplimab in advanced cutaneous 
squamous-cell carcinoma. N Engl J Med 2018;379:341-51.

5. Palyca P, Koshenkov VP, Mehnert JM. Developments in the treatment of locally advanced and metastatic squamous cell carcinoma of the skin: a rising unmet need. Am Soc Clin Oncol Educ Book 2014;e397-404.

doi: $10.21037 /$ sci-2020-071

Cite this article as: Ashraf S, Alsharedi M. Response of advanced cutaneous squamous cell carcinoma to immunotherapy: case report. Stem Cell Investig 2021;8:19. 